\title{
Effects of the Sintering Temperature on the Structure and Properties of the Alumina Foamed Ceramics
}

\author{
Caiyun JIA ${ }^{1}$, Juncheng LIU $^{1, *}$, Rui DING ${ }^{1}$, Dongxiao TENG ${ }^{1}$ and Lijie FENG ${ }^{2}$ \\ ${ }^{1}$ Shandong University of Technology, Shandong 255049, China \\ ${ }^{2}$ Zibo Luzhong Refractory Co., Ltd, Shandong 255138, China
}

\begin{abstract}
Alumina foam ceramics reinforced with alumina fibers were prepared with gel-casting. The effects of the sintering temperature on the foam ceramics were investigated. The foam ceramics were composed of $\alpha-\mathrm{Al}_{2} \mathrm{O}_{3}, \mathrm{C}-\mathrm{AlPO}_{4}$, and T-AlPO ${ }_{4}$ phases. And the mount of T-AlPO $\mathrm{A}_{4}$ phase decreased, while the mount of $\mathrm{C}-\mathrm{AlPO}_{4}$ phase increased once the sintering temperature exceeded $1180^{\circ} \mathrm{C}$ due to the phase transformation of T-AlPO to $\mathrm{C}-\mathrm{AlPO}_{4}$ phase. The grain average size of the foam ceramic increased obviously with the sintering temperature rise, so did its bulk density. While its open porosity decreased. The compression strength of the foam ceramic continuously increased with the sintering temperature rise from 980 to $1580{ }^{\circ} \mathrm{C}$.
\end{abstract}

Keywords: Foamed ceramics; Alumina; Aluminum hydroxide; sintering temperature.

\section{Introduction}

Alumina porous ceramic has many unique properties, such as high hardness, high temperature resistance, and erosion resistance etc ${ }^{[1-4]}$.The main materials to form alumina porous ceramics is cheap and easy to get for its rich sources, and the preparation technique is simple. All these imply great commercial value ${ }^{[5]}$. The sintering temperature has great influence on the properties of the foamed ceramics. Delbrücke et al. fabricated porous $\mathrm{Al}_{2} \mathrm{O}_{3}$ ceramic with porosity of $40.7 \%$ and thermal conductivity of $1.63 \mathrm{~W} /(\mathrm{m} \cdot \mathrm{K})$ by cotton fibers. Samples were sintered at $1600{ }^{\circ} \mathrm{C}{ }^{[6]}$. Nait-Ali et al. got ceramic with a porosity of $40 \sim 75 \%$ and a thermal conductivity $0.8 \sim 9 \mathrm{~W} /(\mathrm{m} \cdot \mathrm{K})$ using polymer as pore-forming agent. Samples were sintered at $1400{ }^{\circ} \mathrm{C}{ }^{[7]}$. Shimizu et al. fabricated $\mathrm{Al}_{2} \mathrm{O}_{3}$ refractory bricks with $90 \sim 97.5 \%$ porosity by a slurry gelation and foaming method, which were sintered at $1500{ }^{\circ} \mathrm{C}{ }^{[8]}$. However, some drawbacks limited the porous ceramic's applications, such as poor shock resistance, and the low strength. The fibers with high modulus and high strength have been

* Corresponding author: jchliu@sdut.edu.cn 
used to reinforce the ceramic matrix to prepare composites, called fiber reinforced ceramics matrix composites (FRCMC), which attracted much more attention due to its excellent properties, such as high temperature oxidation resistance, high strength, high elastic modulus, good rigidity, and good chemical stability. The study and application on dense FRCMC have achieved great success ${ }^{[9-14]}$

Here was the alumina fiber used to reinforce an alumina foam ceramic, which were prepared with gel-casting. The effects of the sintering temperature on the foam ceramics were investigated.

\section{Experiment Procedures}

The starting materials included high purity alumina powder $\left(\mathrm{Al}_{2} \mathrm{O}_{3}, d_{50}=0.5 \mu \mathrm{m}, 99.99 \%\right)$, H-WF-3 ultra-fine aluminum hydroxide powder $\left(\mathrm{Al}(\mathrm{OH})_{3}, d_{50}=3.16 \mu \mathrm{m}, 64.9 \%\right.$ alumina $)$, OP emulsifier (with HLB value 14.5), polycrystalline alumina fibers (97\% alumina), and aluminum dihydrogen- phosphate $\left(\mathrm{Al}\left(\mathrm{H}_{2} \mathrm{PO}_{4}\right)_{3}\right)$ solution $(60 \mathrm{wt} \%)$.

The alumina powder, the aluminum hydroxide powder, the OP emulsifier, and the alumina fiber were added into aluminum dihydrogen phosphate solution sequentially to form a mixture. After stirring for 3-5 minutes, PVA powder (as a foam stabilizer) was add into the mixture, and then the deionized water was added to adjust the mixture viscosity, so a slurry came into being. The slurry was then stirred for $2-3 \mathrm{~h}$ to form uniform foam, till the slurry volume increased no longer. The slurry was casted into disc-shaped mold with diameter of $13.5 \mathrm{~cm}$, standing for $24 \mathrm{~h}$ for the sol's gelling at room temperature. The green body was oven-dried at $50{ }^{\circ} \mathrm{C}$ for about 2 days, and then sintered at high temperature for $4 \mathrm{~h}$ with a heating rate of $10^{\circ} \mathrm{C} / \mathrm{min}$ from the room temperature to the set temperature.

The phase compositions of the sintered specimens were analyzed with X-ray diffractometer (XRD, D8 Advanced, Bruker; $\mathrm{Cu}-\mathrm{K} \alpha, 40 \mathrm{KV}$ ). The micro structures were observed with scanning electron microscopy (SEM, FEI Sirion 200, FEV). Their compression strengths were tested with an electronic universal tester. Their open porosities and bulk densities $\left(D_{\mathrm{b}}\right)$ were measured by the Archimedes method. Their conductivities were measured with THQDC-1 type thermal conductivity detector. The slurry viscosity was examined by a rotational viscometer.

\section{Results and Discussion}

\subsection{Effect of the Sintering Temperature on the Phase Compositions}

In the sintering process, $\mathrm{Al}_{2} \mathrm{O}_{3}, \mathrm{Al}(\mathrm{OH})_{3}$ and $\mathrm{Al}\left(\mathrm{H}_{2} \mathrm{PO}_{4}\right)_{3}$ can react each other as the following equations:

$$
\begin{aligned}
& \mathrm{Al}_{2} \mathrm{O}_{3}+\mathrm{Al}\left(\mathrm{H}_{2} \mathrm{PO}_{4}\right)_{3} \rightarrow 3 \mathrm{AlPO}_{4}+3 \mathrm{H}_{2} \mathrm{O} \\
& 2 \mathrm{Al}(\mathrm{OH})_{3}+\mathrm{Al}\left(\mathrm{H}_{2} \mathrm{PO}_{4}\right)_{3} \rightarrow 3 \mathrm{AlPO}_{4}+6 \mathrm{H}_{2} \mathrm{O}
\end{aligned}
$$

Figure 1 shows the XRD patterns of the specimens sintered at different sintering temperatures. It could be seen that the sintered sample was composed of $\alpha-\mathrm{Al}_{2} \mathrm{O}_{3}, \mathrm{C}-\mathrm{AlPO}_{4}$ and $\mathrm{T}-\mathrm{AlPO}_{4}$. 


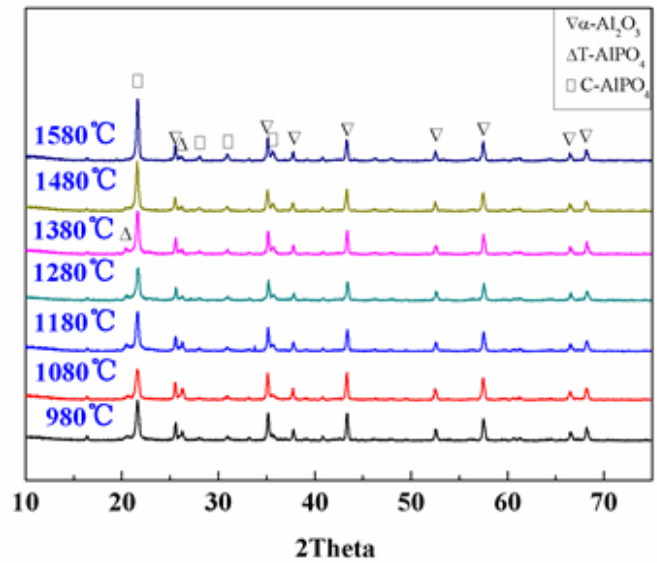

Figure 1 The effect of the sintering temperature on XRD patterns of the specimens

It was worth noting that the peak intensity of $\mathrm{C}-\mathrm{AlPO}_{4}$ phase increased with the sintering temperature increase. On the contrast, the peak intensity of $\mathrm{T}-\mathrm{AlPO}_{4}$ phase decreased, and that of $\alpha-\mathrm{Al}_{2} \mathrm{O}_{3}$ phase almost kept a constant. One reason should be that the crystallinity of T-AlPO 4 phase improved as the sintering temperature rose. Another reason might be attributed to the phase transformation of T- $\mathrm{AlPO}_{4}$ to C-AlPO 4 phase occurred at $1219^{\circ} \mathrm{C}{ }^{[12]}$.
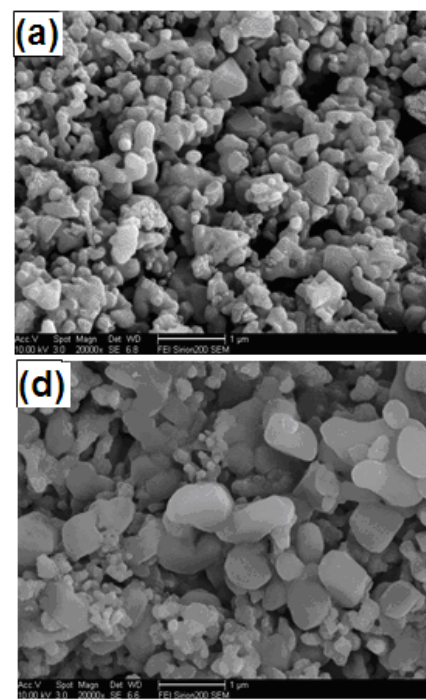
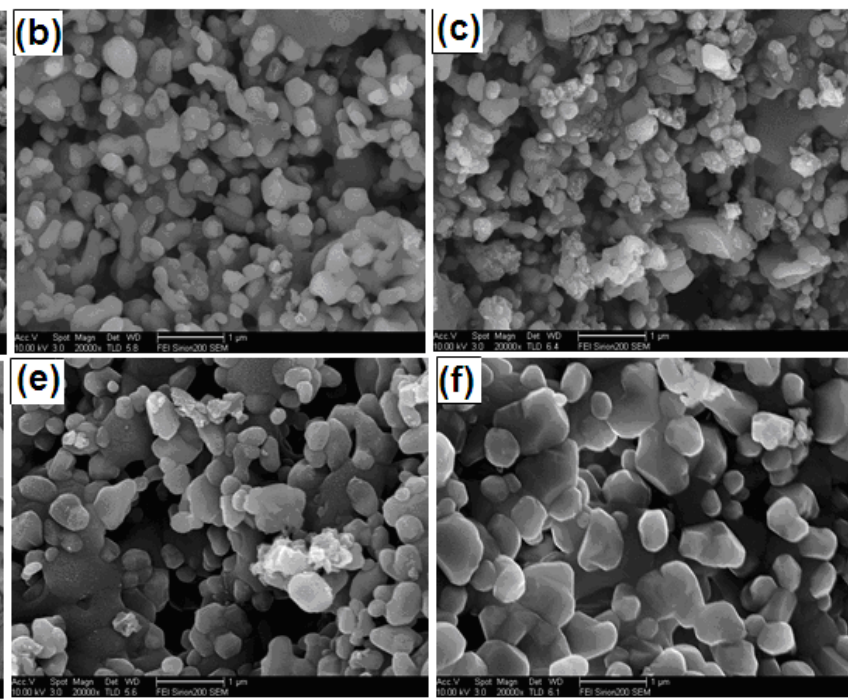

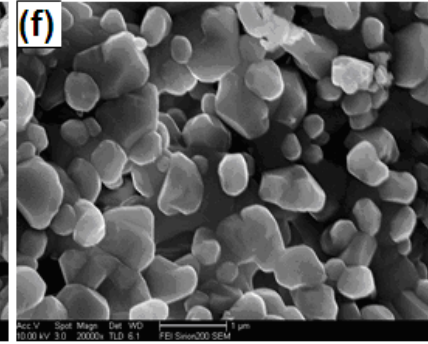

Figure 2 The effect of the sintering temperature on the specimens' microstructure $(20000 \times)$
(a) 980 ;
(b) $1080^{\circ}$
(c) $1180^{\circ} \mathrm{C}$;
(d) $1380^{\circ} \mathrm{C}$; (e)
(e) $1480^{\circ} \mathrm{C}$;
(f) $1580^{\circ} \mathrm{C}$.

\subsection{Effect of the Sintering Temperature on the Foam Ceramic Microstructure}

Figure 2 shows the micro structures of the specimens sintered at different temperature. In general, the average grain size increased with the sintering temperature increase. However, there was a mutation of the grains' morphology and average size between figure 2(c) and 2(d). And it seemed that the microstructure in figure 3(d) was more compact than that in figure 3(c). In figure 2(a) to 2(c), the fine grains dominated the micro structure visual field, 
while the fine grains and the coarse ones were half each. And the coarse grains dominated the micro structure visual field in figure 3(e) and 3(f).

\subsection{Effect of the Sintering Temperature on the Surface Morphology of the Embedded Fibers}

Figure 3 show the microstructures of the fibers embedded in foam ceramics sintered at $1180^{\circ} \mathrm{C}, 1380{ }^{\circ} \mathrm{C}$, and $1580{ }^{\circ} \mathrm{C}$, respectively. Seen from figure $3(\mathrm{a})$, both the end surface and the cylinder surface of the fiber were clean and smooth. This means that the sintering at $1180^{\circ} \mathrm{C}$ damnified little the alumina fibers. In figure 3(b), the fiber's surface became a little rough. The end surface roughness increased further, and even the cylinder surface was already indistinct in figure 3(c). It was clear that the sintering at $1380{ }^{\circ} \mathrm{C}$ or higher temperature would degrade the fiber in a great deal. The $\alpha-\mathrm{Al}_{2} \mathrm{O}_{3}$ grains in the fiber would coarsen, and even react with other phases at such a high temperature.
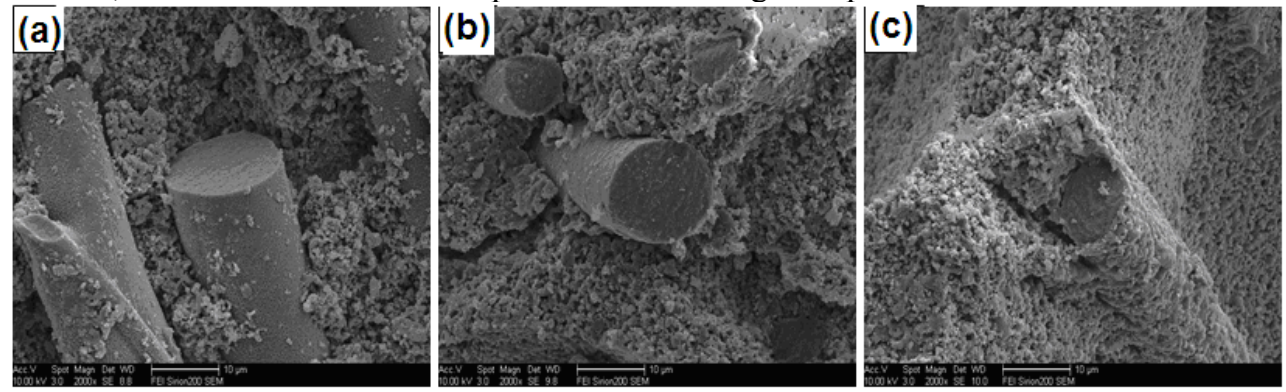

Figure 3 The effect of fibers microstructure in different temperature $(\times 2000)$

\subsection{Effect of the Sintering Temperature on the Foam Ceramic Properties}

In figure 4 , the open porosity of the foam ceramic decreased from $82.47 \%$ to $74.92 \%$ with the sintering temperature rise, while its bulk density increased. As the sintering temperature increased, the grains were easier to grow up, the tiny grains were easier to merge each other, and the grains easier to reassemble. This could be confirmed by figure 2 . Therefore, the open porosity reduced.

The compression strength as a function of the sintering temperature is shown in figure 5 . It is clear that the compression strength continuously increased with the sintering temperature rise, which could be attributed to the porosity's decrease and the bulk density's increase.

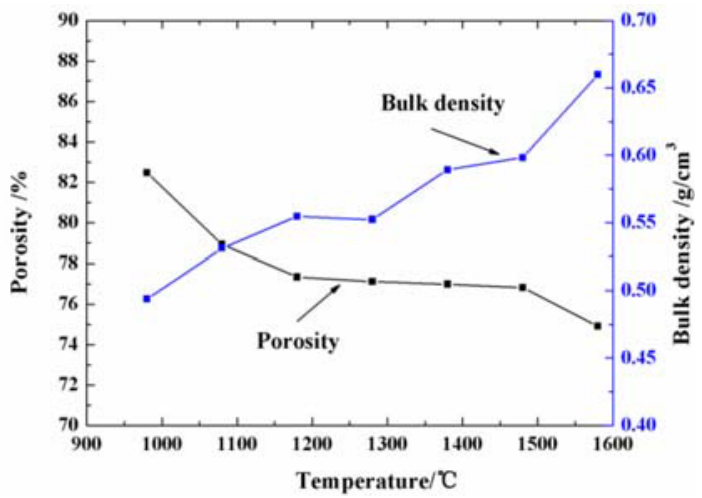

Figure 4 The effect of the sintering temperature on the porosity and the bulk density of the foam ceramic 


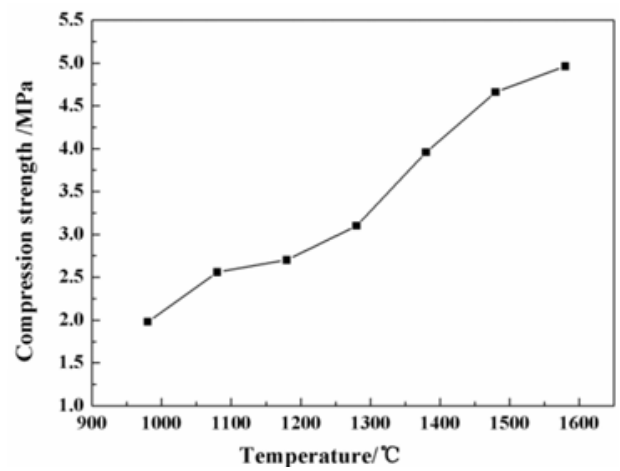

Figure 5 The effect of the sintering temperature on the compression strength of the foam ceramic

\section{Conclusions}

Alumina foam ceramics were prepared with gel-casting, in which high-purity alumina powder was taken as the main material, aluminum dihydrogen phosphate as the adhensive agent, $\mathrm{Al}(\mathrm{OH})_{3}$ as the accelerator, and alumina fibers as the reinforcing agent. The effects of the sintering temperature on the foam ceramics were investigated.

(1) The foam ceramics were composed of $\alpha-\mathrm{Al}_{2} \mathrm{O}_{3}, \mathrm{C}-\mathrm{AlPO}_{4}$, and T-AlPO $\mathrm{O}_{4}$ phases. And the mount of T-AlPO 4 phase decreased, while the mount of C-AlPO 4 phase increased once the sintering temperature exceeded $1180^{\circ} \mathrm{C}$ due to the phase transformation of $\mathrm{T}-\mathrm{AlPO}_{4}$ to C-AlPO 4 phase.

(2) The grain average size of the foam ceramic increased obviously with the sintering temperature rise, so did its bulk density. While its open porosity decreased.

(3) The compression strength of the foam ceramic continuously increased with the sintering temperature rise from 980 to $1580{ }^{\circ} \mathrm{C}$.

\section{Acknowledgements}

This work was financially supported by Project on independent innovation and achievements transformation of Shandong province, Grant No. 2014ZZCX01402.

\section{References}

1. R Gaza, E G Yukihara, S.W.S Mckeever. The response of thermally and optically stimulated luminescence from $\mathrm{Al}_{2} \mathrm{O}_{3}$ : $\mathrm{C}$ to high-energy heavy charged particles, Radiation Measurements 38 (2004): 417-420.

2. T. Dai, X.M. Guo, Pei, Effects of MCAS glass additives on dielectric properties of $\mathrm{Al}_{2} \mathrm{O}_{3}-\mathrm{TiO}_{2}$ ceramics, Mater. Sci. Eng. A 475 (2008): 76-80.

3. L.Y. Shen, M.J. Liu, X.Z. Liu, Thermal shock resistance of the porous $\mathrm{Al}_{2} \mathrm{O}_{3} / \mathrm{ZrO}_{2}$ ceramics prepared by gel casting, Mater. Res. Bull. 42 (2007): 2048-2051.

4. M. Gonzalez, E.R. Hodgson, Electrical and mechanical behavior of improved platinum on ceramic bolometer, Fusion Eng. Des. 82(2007): 1277-1281. 
5. M. Wang, J.B. Wang, Research progress of porous alumina ceramics, App. Chem. Industry, 42 (2013): 1505-1507.

6. T. Delbrücke, R.A. Gouvêa, M.L. Moreira, C.W. Raubach, J.A. Varela, E. Longo, Sintering of porous alumina obtained by biotemplate fibers for low thermal conductivity applications, J. Eur. Ceram. Soc. 33 (2013) 1087-1092.

7. B. Nait-Ali, K. Haberko, H. Vesteghem, J. Absi, D.S. Smith, Preparation and thermal conductivity characterisation of highly porous ceramics, J. Eur. Ceram. Soc. 27 (2007) $1345-1350$.

8. T. Shimizu, K. Matsuura, H. Furue, K. Matsuzak, Thermal conductivity of high porosity alumina refractory bricks made by a slurry gelation and foaming method, J. Eur. Ceram. Soc. 33 (2013) 3429-3435.

9. Y.L. Wang, J.J. Hao, Z.M. Guo, Study on the influencing factors of green strength by Gelcasting, J. Mater. Sci. Eng. 25 (2007): 262-264.

10. S.H. Lee, W. Markus, A. Fritz, Fabrication of fiber-reinforced ceramic composites by the modified slurry infiltration technique, J. Am. Ceram. Soc. 90 (2007): 2657-2660.

11. C.H. Michael, D. James, C. McGuffin, Oxidation kinetics and stress effects for the oxidation of continuous carbon fibers within a microcracked $\mathrm{C} / \mathrm{SiC}$ ceramic matrix composite, J. Am. Ceram. Soc. 91 (2008): 519-526.

12. E.E. Boakye, R.S. Hay, M.D. Petry, T.A. Parthasarathy, Zirconia-silica-carbon coatings on ceramic fibers, J. Am. Ceram. Soc. 87 (2004): 1967-1976.

13. S.M. Goushegir, P.O. Guglielmi, J.G. da Silva, M.P. Hablitzel, D. Hotza, H.A. Al-Qureshi, R. Janssen, Fiber-matrix co MPatibility in an all-oxide ceramic composite with RBAO matrix, J. Am. Ceram. Soc. 95 (2012): 159-164.

14. S.H. Li, H.Y. Du, A.R. Guo, H. Xu, D. Yang, Preparation of self-reinforcement of porous mullite ceramics through in situ synthesis of mullite whisker in fly ash body, Ceram. Inter. 38 (2012): 1027-1032. 